\section{METALURGIA EN LA EDAD DEL BRONCE: EL SUR DE LA CUENCA MEDIA DEL EBRO}

\author{
BRONZE AGE METALLURGY: THE \\ SOUTH OF THE MIDDLE EBRO BASIN
}

\author{
MARÍA JESÚS RODRÍGUEZ \\ DE LA ESPERANZA (*)
}

\section{RESUMEN}

El objetivo de la investigación ha sido conocer el papel que desempeñó la metalurgia en las sociedades de la Edad del Bronce en el Sur de la Cuenca Media del Ebro. Los resultados de los análisis espectrográficos sobre una muestra de minerales metálicos y de artefactos metálicos de la misma zona se han puesto en relación con las posibilidades extractivas reales de las menas por parte de las gentes de la Edad Bronce. Además se estudiaron otros aspectos como la distribución de los artefactos y de los yacimientos de la época, las capacidades de los metalurgistas, y su función y representación social. El resultado deja a la metalurgia prehistórica de la zona en un justo término, apareciendo en el inicio de la Edad del Bronce como una actividad que conferiría prestigio y con escaso peso económico, que iría modificando su importancia al final del período.

\begin{abstract}
This paper deals with the role of metallurgy in the Middle Ebro Basin during Bronze Age with regard to the analytical results on copper mineral and copper/bronze artefact samples in connection with the real possibilitites of mining work. Other's aspects were also studied, such as artefact and site distribution, metallurgic abilities and

(*) Departamento de Prehistoria. Facultad de Geografía e Historia. Universidad Complutense de Madrid. Ciudad Universitaria, s/n. 28040 Madrid.

El artículo fue remitido en su versión final el 11-XI-96.
\end{abstract}

social function. The evidences of metallurgical activities are scarce due to the lack of systematic research. The conclusion is that the first metallurgy seems to be more a prestigious activity than an economic one.

Palabras clave: Metalurgia. Minería. Edad del Bronce. Sur del Medio Ebro. Análisis espectrográficos. Desarrollo social.

Key words: Metallurgy. Mining. Bronze Age. South of Middle Ebro Basin. Spectrographic analysis. Social development.

\section{INTRODUCCIÓN}

Este artículo se enmarca en el Proyecto de Investigación de la DGCYT (PB92-0315): “Arqueometalurgia de la Península Ibérica. Tecnología y cambio cultural durante la Edad del Bronce". Su finalidad última es conocer cuál fue el papel que desempeñó el metal en las sociedades de la Edad del Bronce en el Sur de la Cuenca Media del Ebro (Fig. 1 a).

El estudio de la tecnología en las sociedades prehistóricas requiere tratar aspectos como el descubrimiento, la invención, la innovación, la imposición de ésta sobre la tecnología tradicional, así como su valor económico y el prestigio social vinculado a sus productos. Las investiga- 

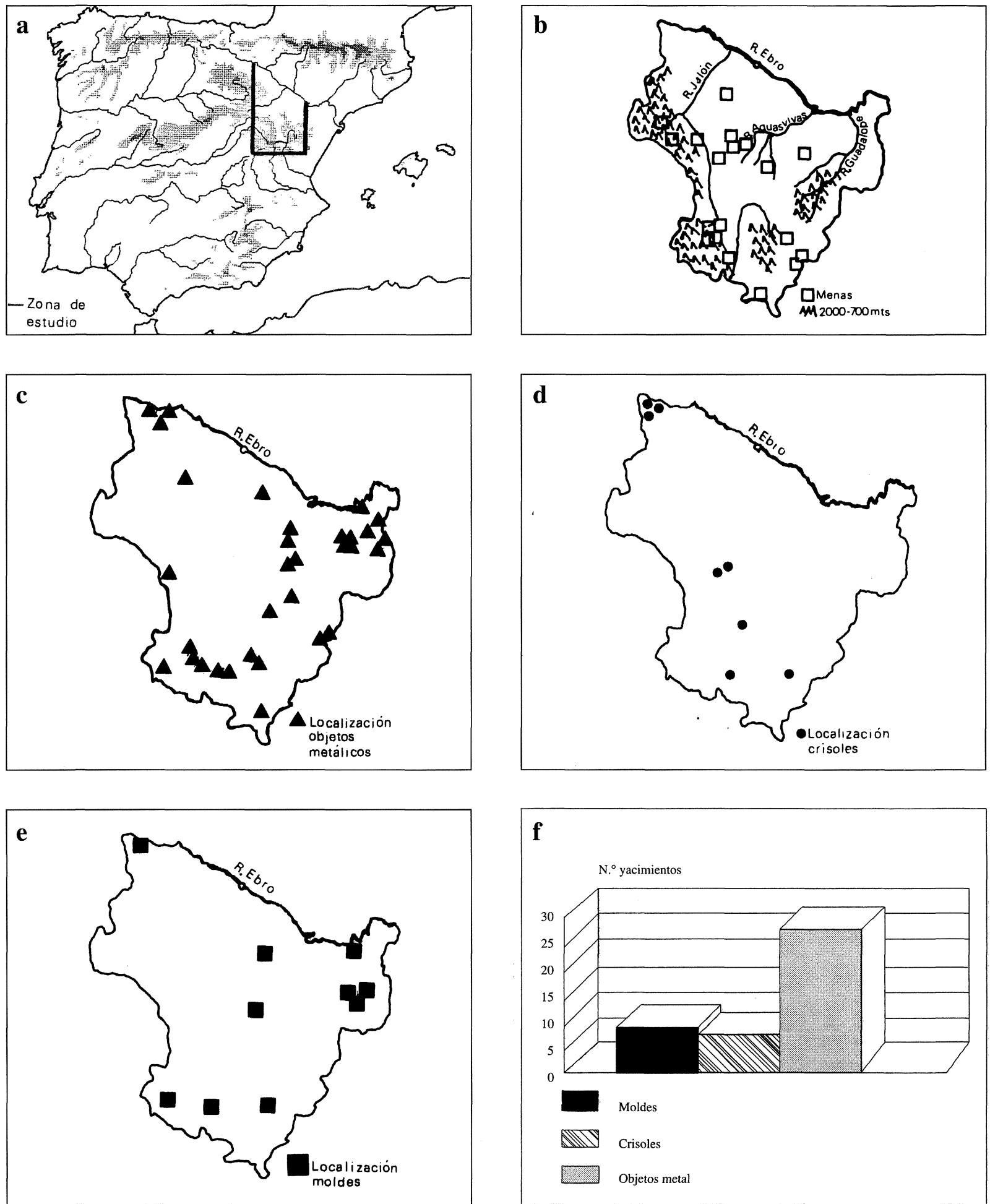

Fig. 1. a: Localización de la zona de estudio; b: Situación de las menas y altimetría de la zona; c: Localización de los objetos metálicos; d: Localización de los crisoles; e: Localización de los moldes; f: Histograma de la producción metalúrgica por número de yacimientos.

T. P., 53, n. ${ }^{\circ} 2,1996$ 
ciones realizadas hasta la fecha sobre el desarrollo de la metalurgia en el Sureste (Montero, 1994), Levante (Bernabeu et alii, 1989; Simón, 1995) y Meseta Sur (Montero et alii, 1990), de la Península Ibérica y algunos otros sobre las regiones de la Europa Atlántica o Mediterránea (Tylecote, 1986; Budd et alii, e.p.) han ofrecido una panorámica rica en matices en lo que se refiere a distribución de materias primas, comercio y transporte tanto de éstas como de sus formas semielaboradas y de objetos acabados, desarrollo de la técnica y papel económico y social de los metalurgistas. El estudio de estos mismos aspectos en el Sur de la Cuenca Media del Ebro no viene sino a completar esta panorámica de la Península Ibérica, con vistas a un futuro trabajo del mismo tipo aplicado a la totalidad de la Cuenca del Ebro.

La elección de la zona de estudio (Fig. 1 a y b) vino dada por sus características geográficas. La orografía de este espacio geográfico es complicada, pero delimita claramente el terreno de estudio. El río Ebro demarca por el Norte la región. La Sierra del Moncayo, la Sierra de la Virgen, la de Miraña, Santa Cruz, Menera y AlbarracínMontes Universales limitan de Norte a Sur por el Oeste. La Sierra de Javalambre se sitúa al Sur, mientras que por el Este y de Norte a Sur, se disponen el río Matarraña y el Maestrazgo.

\section{RECURSOS MINERALES Y EVIDENCIAS DE EXTRACCIÓN EN EL SUR DEL MEDIO EBRO}

Tradicionalmente se comparte la idea de la exigüidad de los recursos cupríferos en el Sur del Medio Ebro (Alvarez Gracia, 1980; Martín Bueno y Pérez Arrondo, 1989; Coffyn, 1985). La interpretación general suministrada por el IGME (1971) resulta insuficiente y poco detallada al mostrarse en los mapas zonas interesantes para la extracción industrial, parámetro no aplicable a un estudio sobre la metalurgia en la Prehistoria. Por ello se hace necesario además emplear datos complementarios más específicos.

En este caso se manejan dos tipos de referencias sobre la zona a partir de los cuales se diseñó una prospección sobre el terreno: A. Distribución general de minerales de cobre basada en los estudios del IGME (1972; Galán y Mirete, 1979) y del Gobierno de Aragón (1995). B. Noticias de antiguos trabajos de minería (Carbonel, 1958).

A. Las mineralizaciones generales se han agrupado según su aparición geológica natural: elemento nativo, óxidos, carbonatos, sulfuros, sulfatos, fosfatos y silicatos (Galán y Mirete, 1979: 98). Hay indicios de cobre nativo en Biel (Zaragoza) y en forma de óxido de cobre (cuprita), en Biel y Ateca (Zaragoza) asociada a limonita, cobre nativo, malaquita, azurita, y crisocola. Encontramos azurita y malaquita (carbonatos de cobre) en el Frasno y Litago (Zaragoza), y como cemento de pudingas en Biel. También ha habido indicios de mineralizaciones concentradas en Collado de la Plata y en las Cavernas del Collado de la Esperanza (Teruel) con cuarzo teñido de verde (Galán y Mirete, 1979: 368). La tetraedrita "Fahlerz" o "cobres grises" aparece en Zaragoza y Teruel: argentífera y asociada a carbonatos y óxidos de hierro, en Ateca. El yacimiento de Calcena (Zaragoza) es el más importante. En Teruel hay citas de su existencia en la Sierra de Albarracín, en donde no es raro encontrarla muy ferrífera y con algo de zinc. La calcopirita (sulfuro de cobre) se encuentra de forma diseminada al norte de la provincia de Teruel, en la Sierra de Albarracín y en Fombuena (Zaragoza).

En Tabuenca se localizan unos indicios de cobre interestratificado en la serie roja continental del Buntsandstein. Los minerales más abundantes son los carbonatos de cobre (azurita y malaquita) y aparecen impregnando los restos orgánicos y rellenando fracturas y planos de laminación.

En Zaragoza hay indicios estratiformes de cobre en Castilicar, Uncastillo, Luesia, Fuencalder y Lobera de Onsella (todos ellos sobre areniscas terciarias), e indicios indeterminados en los municipios de Zaragoza: Santa Eulalia de Gállego, Ardisa, Luna, Villafeliche, Linares de Mora y Villel. Podríamos denominar como otros indicios los detectados sobre areniscas y dolomías del Cretácico cerca del río Linares, el hallado en la confluencia de los ríos Turia y Camarena sobre margas del Cretácico y el hallado sobre areniscas y arcosas del Triásico, todos ellos en Teruel. 


\begin{tabular}{|c|c|c|c|c|c|c|c|c|c|c|}
\hline N. ${ }^{\circ}$ Anál. & $\mathrm{Fe}$ & $\mathrm{Ni}$ & $\mathrm{Cu}$ & $\mathrm{Zn}$ & As & $\mathrm{Ag}$ & Sn & $\mathrm{Sb}$ & $\mathrm{Pb}$ & $\mathrm{Bi}$ \\
\hline L. T. (*): & & & & & & & & & & \\
\hline PA6907A & 2,275 & n.d. & 90,137 & n.d. & 5,741 & 0,033 & n.d. & 1,581 & n.d. & n.d. \\
\hline PA6907B & 1,591 & n.d. & 93,71 & n.d. & 4,065 & 0,103 & n.d. & 0,530 & n.d. & n.d. \\
\hline PA6908A & 2,293 & n.d. & 20,21 & n.d. & 20,21 & 0,022 & n.d. & 0,216 & n.d. & n.d. \\
\hline PA6908B & 0,758 & n.d. & 78,27 & 2,098 & 16,96 & 0,019 & n.d. & 1,902 & n.d. & n.d. \\
\hline PA6908C & 10,27 & n.d. & 59,86 & n.d. & 26,56 & 0,073 & n.d. & 3,241 & n.d. & n.d. \\
\hline PA6908D & 0,567 & n.d. & 72,77 & 1,953 & 24,01 & 0,014 & n.d. & 0,691 & n.d. & n.d. \\
\hline PA6908E & 1,42 & 0,676 & 66,96 & 0,96 & 28,77 & 0,118 & n.d. & 1,085 & n.d. & n.d. \\
\hline PA6908F & 2,783 & n.d. & 86,77 & n.d. & 9,206 & 0,312 & n.d. & 0,924 & n.d. & n.d. \\
\hline PA6908G & 0,955 & n.d. & 96,69 & n.d. & 1,433 & n.d. & n.d. & 0,923 & n.d. & n.d. \\
\hline PA6908H & 2,093 & n.d. & 87,73 & 0,449 & 7,059 & n.d. & n.d. & 2,754 & n.d. & n.d. \\
\hline Media & 2,5 & & 75,31 & 1,115 & 14,40 & 0,086 & & 1,384 & & \\
\hline STD & 2,82 & & 22,75 & 0,697 & 10,1 & 0,099 & & 0,984 & & \\
\hline \multicolumn{11}{|l|}{ M.H.: } \\
\hline PA7361A & 13,70 & 0,647 & 85,60 & n.d. & n.d. & n.d. & n.d. & 0,017 & n.d. & n.d. \\
\hline PA7361B & 27,24 & n.d. & 71,70 & n.d. & n.d. & n.d. & n.d. & 0,046 & n.d. & n.d. \\
\hline PA7361C & 6,900 & n.d. & 92,50 & n.d. & 0,544 & n.d. & n.d. & 0,010 & n.d. & n.d. \\
\hline PA7361D & 4,495 & 0,300 & 95,20 & n.d. & n.d. & n.d. & n.d. & tr. & n.d. & n.d. \\
\hline PA7361E & 9,597 & n.d. & 90,35 & n.d. & n.d. & n.d. & n.d. & 0,018 & n.d. & n.d. \\
\hline Media & 12,38 & 0,47 & 87,07 & n.d. & & & & 0,022 & & \\
\hline STD & 8,979 & 0,24 & 9,283 & & & . & & 0,015 & & \\
\hline \\
\hline PA7361 & 3,650 & n.d. & 96,33 & n.d. & n.d. & n.d. & n.d. & 0,021 & n.d. & n.d. \\
\hline \multicolumn{11}{|l|}{ B.H.: } \\
\hline PA7402A & 13,90 & n.d. & 40,14 & n.d. & 14,16 & 0,585 & n.d. & 31,18 & tr. & n.d. \\
\hline PA7402B & 16,05 & n.d. & 19,11 & n.d. & 12,35 & 1,174 & n.d. & 46,60 & 4,426 & n.d. \\
\hline PA7402C & 22,81 & n.d. & 33,20 & n.d. & 11,18 & 0,340 & n.d. & 32,17 & n.d. & n.d. \\
\hline PA7402E & 14,17 & n.d. & 77,20 & n.d. & 1,585 & 0,051 & n.d. & 3,807 & 3,105 & n.d. \\
\hline PA7402F & 17,83 & n.d. & 32,35 & n.d. & 11,57 & 0,667 & n.d. & 36,90 & 0,659 & n.d. \\
\hline Media & 16,95 & & 40,40 & & 10,16 & 0,563 & & 30,13 & 2,93 & \\
\hline STD & 3,638 & & 21,93 & & 4,933 & 0,417 & & 15,93 & 2,04 & \\
\hline
\end{tabular}

Tabla 1. Análisis de muestras de minerales (expresada en \% en peso).

(*) L.T.: Loma de la Tejería (Albarracín, Teruel).

(*) M.H.: Mina del Hocino (entre Fombuena y Luesia, Zaragoza).

(*) C: Cucalón (Zaragoza).

(*) B.H.: Barranco de Hontanar (Torres de Albarracín, Teruel).

B. El estudio de Carbonel (1958) sobre la Sierra de Albarracín recoge las concesiones mineras, en qué año se obtuvieron, el material beneficiado, el nombre de la concesión y su superficie en hectáreas. El resumen de los minerales de cobre (y otros) que fueron objeto de concesiones en distintos términos municipales de Teruel es el siguiente:

Albarracín: hierro, cobre, cobre gris y cinabrio.

Bronchales: hierro, cobre gris y azufre.

Gea de Albarracín: plata, cobre y hierro.

Torres de Albarracín: plomo, cobre gris, cobre argentífero y hierro.

Advierte el autor (Carbonel, 1958: 18) que no siempre el criadero es de la sustancia que se declara. Estas son las consecuencias de las lla- madas "falsificaciones de hacienda" que quedaban registradas en los libros con la finalidad de pagar menos impuestos (Pan Montojo, 1993: 337-441) probablemente por la abundancia del hierro y la escasez del cobre.

A partir de ambos estudios se realizaron dos prospecciones para buscar muestras minerales que pudieran ser analizadas dentro del proyecto de Arqueometalurgia de la Península Ibérica (1). Estas prospecciones se llevaron a

(1) Los análisis han sido realizados en el Instituto de Patrimonio Histórico Español (antiguo I.C.R.B.C. del Ministerio de Cultura) con la técnica de Fluorescencia de Rayos X en energías dispersivas. Se ha cuantificado la fracción metálica de las muestras minerales expresadas en $\%$ en peso. 
cabo en julio de 1995 y en febrero de 1996. Se tomaron muestras de diferentes afloramientos localizados en Zaragoza y Teruel y los resultados son los que aparecen en la tabla 1.

Estos análisis establecen más claramente los diferentes grupos mineralógicos. Uno al sur de Zaragoza está formado por minerales de cobre (azurita y malaquita) con presencia de altos niveles de hierro e impurezas de antimonio. La zona de Albarracín se caracteriza por otro grupo de minerales de cobre con altos contenidos de hierro, arsénico y antimonio, en el caso de la Loma de la Tejería van acompañados de zinc mientras que en El Barranco del Hontanar van acompañados de plomo. En estas muestras no se ha detectado el bismuto.

\section{EVIDENCIAS DE PRODUCCIÓN METALÚRGICA: INTERPRETACIÓN DE LA DISTRIBUCIÓN Y DE LOS ANÁLISIS}

\subsection{Relación entre menas de cobre y materiales arqueológicos metálicos}

La distribución de yacimientos de la Edad del Bronce con algún vestigio metálico o de procesado de actividad metalúrgica se refleja en la figura $1 \mathrm{c}$. Se observa una localización de objetos metálicos con preferencia al Noreste, Suroeste, en las medianías del Sistema Ibérico, en la Sierra de Albarracín y en la Sierra del Javalambre, apreciándose también en las inmediaciones del Moncayo.

En su mayoría, las piezas han sido localizadas sin contexto y en superficie, y de otras ni siquiera sabemos su procedencia exacta, lo que nos impide valorarlas tal y como recientemente se ha hecho en otros contextos (Ruíz-Gálvez, 1995: 32). En los estudios que hasta la fecha se han realizado se ha constatado que existen vacíos de yacimientos debidos por un lado a la propia elección de las comunidades prehistóricas del Sur de la Cuenca Media del Ebro (Burillo, 1992: 177-185) y, por otro lado, a la falta de una sistematización en la investigación.

Nos pareció importante analizar la localización geográfica y geológica de los recursos de cobre en la misma. Estos se encuentran de forma filoniana o estratiforme sobre todo en el Suroeste y también de forma filoniana pero no estratiforme, como depósitos aislados y en menor cantidad en el Noreste. Recientemente se ha señalado la existencia de cobre en Collado Mediano (Tabuenca), en las inmediaciones de Litago y Aranda de Moncayo. Las dos puntas palmela encontradas en Litago y Bisimbre y los doce objetos procedentes de las excavaciones de Borja, de Majaladares y de Los Reajos de Beratón parecen indicar la importancia de la proximidad de estos recursos de cobre (García Serrano, 1995: 12). Sin embargo, la existencia de menas no implicaría que fueran explotables durante la Edad del Bronce. La erosión o el desmonte del suelo podrían haber dejado al descubierto afloramientos que en esa época se hallaran ocultos. Ello podría falsear la correlación entre su distribución y la de los yacimientos.

Para demostrar que en la Prehistoria se explotaron estos recursos hacen falta pruebas de minería prehistórica, como el caso de la Loma de la Tejería, y también se necesitan evidencias indirectas a través de la caracterización de los minerales de cobre y de los artefactos metálicos de la zona. En la Península Ibérica los minerales de cobre no producen cobre puro, sino mezclado en diferentes proporciones con otros elementos que caracterizan el metal de cada zona. Lamentablemente, tal y como los geoquímicos han puesto de relieve, la composición del mineral de un mismo criadero puede ser tan diferente y variada que sólo se podrá relacionar de forma segura con un objeto cuando exista la certeza de trabajos de las comunidades prehistóricas en aquel estrato (Tylecote, 1990: 13-31). Existen otras evidencias que pueden tenerse en cuenta, como la cercanía a la mena de herramientas como martillos (La Loma de la Tejería, Albarracín) y picos de minero cuñas o simplemente señales de extracciones en la roca.

La correlación entre la distribución de las piezas y la de los yacimientos cupríferos permite predicar como probable una metalurgia local y una distribución del metal a cortas distancias, sin excluir la posibilidad de una importación de manufacturas y de metal procesado, ya fuera en lingotes de cobre, estaño, o formando ya la aleación. Este tema tan sugerente ha sido trata- 
do y desarrollado a nivel general por Mohen (1991), Gómez Ramos (1993), Lucas y Ramos (1993). Existen evidencias de un comercio muy relevante de lingotes de cobre y estaño en el Mediterráneo oriental a partir de los hallazgos en el mar cercanos a las costas de Israel o los de Chipre y Turquía, entre 1550-1200 A.C. pertenecientes aproximadamente al Bronce Final (Mazar, 1990: 264-266).

La evidencia de un comercio de metales durante la Edad del Bronce no resta interés a las investigaciones sobre las posibilidades metalogenéticas no industriales de la Cuenca del Ebro que no se adscriben a la teoría unifocal. Según esta última, los minerales proceden de lugares alejados del entorno del Ebro, excluyendo que pudieran darse varias situaciones simultáneas: explotación y producción local y explotación y producción alóctona de piezas posteriormente importadas que favorecería su reutilización dado su valor tanto intrínseco como adquirido.

Además, la cercanía o no a la mina de vasijas-horno, crisoles y moldes, con sus adherencias y sus escorias que denotan la transformación del metal (Montero, 1994: 228) y la producción de objetos pueden indicar si el proceso se daba en aquel mismo lugar o en otros más lejanos a donde se transportaba el mineral bruto y donde se procesaba, pudiendo ser estos lugares centros productores y distribuidores.

\subsection{Evidencias de la transformación y producción}

\subsubsection{Vasijas-horno y crisoles}

Los fragmentos cerámicos con adherencias metálicas no son infrecuentes en la Península Ibérica (Gómez Ramos, 1996: 127-143). Se conocen en el Neolítico del Sureste (Montero, 1996: 28-30; Montero y Ruíz, 1996) pero se generalizan tanto en el Levante como en la Meseta con posterioridad (Gil Mascarell, 1995: 65). Lo difícil es diferenciar los fragmentos cerámicos que realmente pertenecieron a crisoles de aquéllos definidos como vasijas-horno, ya que en la bibliografía en su mayoría se describen como fragmentos de crisol con adherencias. Según un estudio reciente las vasijas-horno serí- an de poco fondo y sección abierta (Montero, 1993: 51), su función sería la de procesar el mineral para obtener el metal, separando la ganga. Por el contrario, los crisoles parecen tener una sección más cerrada y su función es la del licuado del metal ya refinado. Las implicaciones técnicas de una u otra actividad son muy distintas $\mathrm{y}$, por tanto, su diferenciación es fundamental.

Las adherencias de cobre en las paredes interiores de los recipientes pueden relacionar los objetos ya procesados con las zonas donde, según los análisis, podría haberse extraído el mineral (Craddock, 1985; Marechal, 1985; Montero, 1994) (Fig. 1b).

El fragmento de "crisol" con adherencia de cobre en el yacimiento de La Hoya Quemada (Mora de Rubielos, Teruel; C-14: XX-XVIII B.C.) revelaría una fase de producción en alguno de los yacimientos y, el de escoria de $\mathrm{La}$ Peña Dorada (Alfambra, Teruel; C-14: XXIXIX B.C.), actividades de reciclaje (Picazo Millán, 1993: 47 y 107 repectivamente).

Además, en la Hoya Quemada aparecieron punzones de bronce y una punta tipo palmela de cobre. Los autores propusieron el tipo de aleación en función de la coloración de los metales. En todo caso es muy interesante que, en niveles pertenecientes a los siglos XX-XVIII B.C. y XVII-XVI B.C. (Burillo Mozota y Picazo Millán, 1992), aparezcan tanto elementos de transformación metalúrgica como de producción (nos referimos al molde que allí se encontró). Sería útil analizarlos para precisar exactamente la composición de los primeros y si existen restos en los segundos.

Según Picazo Millán (1991: 79), la aparición de posibles crisoles con adherencias de cobre en El Picurucho de Bañón y Las Lomas de Torrijo del Campo (Calamocha, Teruel) evidencian el desarrollo de actividades metalúrgicas en los poblados de la Edad del Bronce seguramente en un ámbito doméstico. Los recipientes habrían estado destinados tanto al reciclaje de piezas inútiles, como a la transformación final del mineral procedente de los pequeños afloramientos en el entorno de las Sierras de Palomera-Lidon.

Picazo Millán (1991b) paraleliza los niveles de procedencia de los recipientes con adherencias de Tajada Bajera y La Escondilla (Villas-

T. P., 53, n. ${ }^{\circ} 2,1996$ 
tar, Teruel) con la segunda fase de La Hoya Quemada del Bronce Medio. Al Noroeste de la región que estudiamos, tenemos noticias de otros tres enclaves en donde se han localizado otros tantos fragmentos de cerámica con adherencias metálicas. En Moncín de Borja (Zaragoza) los análisis del British Museum de la escoria incrustada en fragmentos de crisol (Harrison et alii, 1987: 71) sugieren un recipiente para fundir metal limpio. Muy cerca, en Majaladares, se hallaron restos de un crisol con adherencias de cobre y gotas del mismo metal (Aguilera et alii, 1992: 44 y 75) y el de Siete Cabezos (Magallón, Zaragoza) estaba decorado con incisiones en el labio y con incrustaciones escoriáceas en el interior (Aguilera et alii, 1990: 71-74).

No podemos por ahora confirmar la función de los hallazgos de nuestra zona (Fig. 1d). Su diferenciación es fundamental para la interpretación: si el mineral se fundió en vasijas no tendríamos que seguir buscando hornos, por otra parte, el empleo de crisoles lleva consigo el de moldes, por lo que la proliferación o ausencia de estos últimos en zonas como el Bajo Aragón o Albarracín debe tener alguna explicación. Si el mineral fue fundido en las vasijas-horno directamente y en pequeñas cantidades no hay duda de que la metalurgia no representaría la base económica fundamental de aquellas sociedades.

\subsubsection{Moldes}

Estos son más numerosos que los crisoles en la zona estudiada (Fig. 1e). Treinta y cinco moldes han aparecido en poblados pero de casi ninguno conocemos el nivel de procedencia. Once pertenecen a un Bronce Antiguo/Medio y veinticuatro a la etapa final del Bronce. Los más antiguos se hallaron en La Hoya Quemada (Mora de Rubielos, Teruel), La Escondilla (Villastar, Teruel), Cueva de los Encantados (Belchite, Zaragoza) y Cabezo del Cuervo (Alcañiz, Teruel) y los más modernos son de Siriguarach (Alcañiz, Teruel), Cabezo del Cascarujo (Alcañiz, Teruel) y Cabezo de Monleón (Caspe, Zaragoza).

Todos los moldes conservados están realizados sobre arenisca rosada de granulado fino que fue empleada también en molinos de tipo barquiforme y afiladores (Domínguez 1981: 22; Aguilera et alii, 1992: 77; Barandiarán, 1971: 45). Actualmente se explotan estas areniscas en el Sur-Sureste de la región, exactamente en La Iglesuela del Cid y Mosqueruela (Teruel) (DGA, 1995: 343). Saber si la propia arenisca o los moldes ya manufacturados fueron objeto de algún tipo de transacción $o$, al menos, de demanda abriría un interesante campo de debate.

Durante el primer período nos encontramos fundamentalmente con dos tipos de moldes: para hachas planas y varillas. Tres de los primeros proceden de: La Hoya Quemada (Juste, 1990: 83), El Cabezo del Cuervo (Benavente Serrano, 1984b: 230), y el Barranco de la Terolana (Simón et alii, 1987-88: 77) y cuatro de La Escondilla de Villastar (Picazo, 1991b: 151). Hay cuatro ejemplares de los segundos en el Cabezo del Cuervo (Benavente, 1971). Además se han encontrado valvas de moldes de morfología sin determinar ya sea por su deterioro o porque no se ha especificado su tipo, caso del hallado en la Cueva de los Encantados de Belchite (Barandiarán, 1971) y de los dos moldes de Moncín de Borja (Harrison et alii, 1987).

En la etapa posterior hay moldes de hachas, escoplos, anillas, puntas de pedúnculo y aletas y varillas en Siriguarach (3 para hachas planas, 1 de talón y una anilla lateral, 1 escoplo, 1 de cinco varillas, 1 flecha de pedúnculo y aletas y 1 molde con tres caras de piezas diversas), en Cabezo de Monleón (11 moldes, uno de ellos para 3 puntas de flecha con pedúnculo y aletas), y en Cabezo del Cascarujo (1 para anillas y 1 para hachas planas) (Catálogo, 1989: 44 y ss.; Benavente, 1984: 228-233; Ruíz Zapatero, 1982: 50).

La mayor densidad de moldes se da en la mitad oriental de la zona que estudiamos. Esto no es extraño ya que, como ya se señaló hace algunos años (Benavente Serrano, 1984: 236), el Bajo Aragón, y los cursos inferiores del Cinca, Segre y Alcanadre, es el área de máxima concentración de moldes en piedra del Noreste y de toda la Península Ibérica, quizás en relación con una vía de comunicación (Ruíz Gálvez, 1995), como el río Ebro, distante apenas unos kilómetros de los yacimientos mencionados. 


\begin{tabular}{|c|c|c|c|c|c|c|c|c|c|c|c|c|}
\hline N. ${ }^{\circ}$ Anál. & Yacimiento & Localidad & Objeto & $\mathrm{Fe}$ & $\mathrm{Ni}$ & $\mathrm{Cu}$ & As & $\mathrm{Ag}$ & Sn & $\mathrm{Sb}$ & $\mathrm{Pb}$ & $\mathrm{Bi}$ \\
\hline PA6975 & La Iglesia & Iglesuela del Cid & Hacha plana & 0,039 & n.d. & 99,31 & 0,4 & 0,016 & 0,019 & 0,005 & n.d. & 0,11 \\
\hline PA6976 & Idem & Idem & Idem & 0,034 & n.d. & 99,60 & 0,3 & 0,003 & n.d. & 0,03 & n.d. & 0,03 \\
\hline PA6977 & La Iglesuela & Idem & Hacha apéndices & 0,178 & 0,24 & 77,50 & 0,4 & 0,110 & 20,89 & 0,378 & n.d. & 0,27 \\
\hline PA6717 & El Castelillo & Alloza & Idem & 0,832 & n.d. & 85,40 & n.d. & n.d. & 13,83 & 0,020 & n.d. & n.d. \\
\hline PA6716 & Provincia & Teruel & Hacha 2 anillas & 0,348 & n.d. & 74,72 & n.d. & 0,028 & 22,00 & 0,120 & n.d. & 2,75 \\
\hline PA6715 & Partida Naves & Alloza & Alabarda & 0,031 & n.d. & 99,75 & 0,2 & 0,011 & n.d. & 0,010 & n.d. & n.d. \\
\hline PA6714 & Idem & Alloza & Hacha plana & 0,198 & n.d. & 99,74 & tr. & 0,019 & n.d. & 0,008 & n.d. & n.d. \\
\hline PA6713 & El Castillo & Frías de Albarracín & Punzón & 0,164 & n.d. & 96,74 & 3,1 & n.d. & n.d. & n.d. & n.d. & n.d. \\
\hline PA6712 & Idem & Idem & Punzón & 0,123 & 0,15 & 97,60 & 1,2 & 0,029 & n.d. & 0,777 & n.d. & n.d. \\
\hline PA6711 & Idem & Idem & Punzón & n.d. & n.d. & 85,28 & n.d. & 0,220 & 12,70 & 0,492 & n.d. & 1,31 \\
\hline PA6709 & Idem & Idem & Puñal (fragmento) & n.d. & n.d. & 97,00 & 3,0 & 0,003 & n.d. & n.d. & n.d. & n.d. \\
\hline PA6710 & Sima Ruidor & Aldehuela & Punzón & n.d. & n.d. & 87,38 & n.d. & 0,046 & 12,49 & 0,281 & n.d. & n.d. \\
\hline PA6708 & Idem & Aldehuela & Cincel & 0,109 & n.d. & 92,25 & n.d. & 0,026 & 7,53 & 0,063 & n.d. & n.d. \\
\hline PA6707 & C. Cariñena & Ariño & Hacha plana & 0,191 & n.d. & 97,40 & 0,4 & 0,016 & 1,83 & 0,063 & n.d. & n.d. \\
\hline PA5579 & Las Alhambras & Manzanera & Puñal remaches & 0,162 & 0,28 & 80,16 & 0,3 & 0,019 & 18,89 & 0,154 & n.d. & n.d. \\
\hline PA5566 & Idem & Manzanera & Punta de Palmela & 0,077 & n.d. & 99,62 & 0,2 & 0,014 & tr. & 0,007 & n.d. & n.d.tr \\
\hline PA5565 & Idem & Manzanera & P. pedunculada & 0,162 & 0,26 & 65,21 & n.d. & 0,017 & 34,15 & n.d. & n.d. & n.d. \\
\hline PA5576 & Valdoria & Albalate Arzobispo & Punta de aletas & 0,099 & n.d. & 91,60 & n.d. & 0,053 & 7,61 & 0,018 & n.d. & 0,59 \\
\hline PA5580 & C. Encantados & Belchite & Punzón & 0,110 & 0,17 & 95,96 & n.d. & 0,022 & 3,72 & 0,037 & n.d. & n.d. \\
\hline PA5573 & Idem & Belchite & Punta de aletas & 0,169 & 0,13 & 87,15 & 0,3 & 0,003 & 0,10 & 0,128 & n.d. & n.d. \\
\hline PA5569 & Idem & Belchite & Puñal remaches & 0,113 & n.d. & 97,49 & 0,4 & 0,005 & 4,92 & 0,050 & n.d. & n.d. \\
\hline PA5578 & Majaladares & Borja & Hacha plana & 0,057 & n.d. & 99,42 & 0,4 & 0,009 & 0,01 & 0,018 & n.d. & n.d. \\
\hline PA5588 & Idem & Borja & Hacha plana & 0,032 & n.d. & 99,70 & 0,1 & 0,017 & tr. & 0,015 & n.d. & n.d. \\
\hline PA5585 & Idem & Borja & Punta de aletas & 0,025 & n.d. & 99,22 & 0,6 & 0,002 & n.d. & 0,008 & n.d. & n.d. \\
\hline PA5583 & Moncín & Borja & Punta de aletas & 0,146 & 0,18 & 83,80 & n.d. & n.d. & 15,83 & 0,024 & n.d. & n.d. \\
\hline PA5582 & Idem & Borja & Punta de aletas & 0,053 & 0,06 & 98,80 & n.d. & 0,042 & n.d. & 0,116 & n.d. & n.d. \\
\hline
\end{tabular}

Tabla 2. Composición de los objetos de metal (valores en \% en peso).

Su presencia en los asentamientos, con independencia de la procedencia del metal y de la arenisca, significa que al menos una parte de la producción metalúrgica se llevó a cabo en estos asentamientos. Dicha actividad enlaza subsecuentemente con la que se deriva de la presencia de crisoles.

\subsection{Análisis y estudio de los artefactos metálicos}

\subsubsection{Análisis de las piezas}

De la cifra total de piezas inventariadas se han analizado 26 para conocer la composición (Tabla 2).

En los análisis de la tabla prevalecen los porcentajes de cobre y estaño. A pesar de ser éste un aspecto importante, no lo es menos la presencia de oligoelementos que, en muchas ocasiones, sirven para orientar sobre la procedencia del mineral utilizado. Llama la atención sobre todo la total ausencia del plomo en los análisis practicados, más aún cuando en ciertos filones aragoneses se detecta este polimetalismo natural, asociado a los cobres grises $(\mathrm{Cu}+\mathrm{As}, \mathrm{Cu}+\mathrm{Sb}$ y $\mathrm{Cu}+\mathrm{As}+\mathrm{Sb})$ y a la plata. Hay siete piezas con bismuto ( $\mathrm{Bi}$ ), un elemento poco habitual en los objetos analizados dentro del Proyecto de Arqueometalurgia, que puede ser una de las claves diferenciadoras de las relaciones objeto-mineral que estamos investigando. Este elemento puede encontrarse en la naturaleza asociado bien con As y Sb, bien con estaño, wolframio o molibdenita. En los análisis practicados casi siempre va vinculado al estaño. La paragénesis del bismuto se asocia a las menas de plata y cobalto, y con molibdenita, wolframita, casiterita y bismutina (Galán y Mirete, 1979: 125).

El níquel suele asociarse al cobre y plomo. En nuestro caso también el plomo sólo es detectado en las mineralizaciones y en los siete objetos que contienen níquel sin que se hayan detectado siquiera trazas de plomo. Encontramos la asociación cobre-níquel en la margen derecha del río Guadalaviar. En nuestros aná- 
lisis tan sólo tenemos una pieza con trazas de contener níquel. La asociación plomo-zincplata es muy habitual en la naturaleza donde, incluso, puede aparecer como intrusión de los minerales de cobre. En la zona de estudio, sin ser abundante, podemos encontrarla en Los Monegros cerca de menas de cobre-plomo o en asociaciones tipo cobre-plomo-zinc (Mapa 47, IGME, 1974). Lo mismo sucede en la zona de afloramientos situada en el margen derecho del río Huerva, en la confluencia de la Sierra del Cucalón y la Sierra de Herrera y en el margen derecho del río Aguasvivas (Mapa 40, IGME, 1974).

Tras este estudio la interpretación de la evidencia metalúrgica en nuestra zona resulta más clara. Los minerales utilizados en el procesado podrían haberse obtenido perfectamente en la propia área, porque, como se ha demostrado, se observan las mismas asociaciones en los minerales que en los artefactos metálicos analizados. La contrastación de los datos obtenidos en los análisis de los objetos con la información metalogenética y de los minerales permite proponer las zonas de más probable extracción del mineral. Son las menas cercanas al río Jalón con asociaciones cobre-antimonio-plata y los filones de la Sierra de Albarracín y la zona del río Guadalaviar con asociaciones cobre-hierro, cobre-plata y cobre-plata-antimonio-arsénico. En cambio, por la clase de asociación que se da en Los Monegros, parece menos probable que los minerales extraídos procedieran de allí.

\subsubsection{Análisis tipológico diacrónico}

El estudio tipológico se proponía averiguar cuáles eran las diferencias que se podrían llegar a percibir en las formas y composiciones de los artefactos metálicos durante los períodos de la Edad del Bronce. A partir de un recuento global inicial de 93 objetos (59 metálicos y 34 moldes), establecimos una distribución, distinguiendo entre los propios objetos y sus moldes (Mohen y Balloud, 1987: 130 y ss), diferenciamos 12 tipos y además una categoría de indeterminados ya que su número es muy alto.

Las hachas planas (15), las puntas palmela (11) y las puntas de pedúnculo y aletas (13) son los tipos que más abundan en nuestra región, siempre relacionados con las actividades cinegética y guerrera. Más recientemente se ha empezado a pensar en la posibilidad de que, en concreto, las hachas fuesen objetos con un valor simbólico diferente del mero valor económico (Kristiansen, 1987: 74-85; Randsborg, 1979: 318). Es decir, que la posesión de estos objetos estaría en relación con el prestigio de los individuos y del grupo (Kristiansen, 1987: 79 y 83).

Los restantes objetos representados son: cinco varillas, dos anillas, cuatro hachas con anillas, un cuchillo, un cincel y una alabarda.

Clasificamos los objetos en dos subfases clásicas: 1.-Bronce Antiguo/Bronce Medio y 2.Bronce Tardío/Bronce Final.

1. Bronce Antiguo/Bronce Medio.

Observamos que sobre 59 piezas predominan las hachas planas (11), las puntas palmela (11) y los punzones. (9).

Las puntas palmela se asocian normalmente a Horizontes Campaniformes y Epicampaniformes, pareciendo tener su origen en el Calcolítico final y su desarrollo en el Bronce Inicial. No obstante, se han documentado en contextos mucho más recientes como en la Meseta Norte (Padilla de Abajo) en horizontes del Bronce Final (Rovira et alii, 1988: 269-270). Desde que Delibes (1977) clasificase en 3 grupos las puntas palmela, se ha intentado dilucidar su técnica de fabricación. Los trabajos sobre cobres y los cobres arsenicados mantienen la técnica en frío (Rovira et alii, 1988: 276277). Según los autores mencionados, se aprecia a lo largo del tiempo un incremento en la aplicación del tratamiento térmico en la forja así como su disminución en las aleaciones broncíneas (Fig. 2 j).

El grupo de las hachas planas parece tener relevancia en este período. Han aparecido por lo general de forma aislada y sin una estratigrafía definida en todo el Valle del Ebro (Pérez Arrondo y López de Calle, 1986: 192). Las tipologías que hasta hoy hemos podido revisar las distinguen por su anchura, longitud, espesor y, por supuesto, la forma del filo. Los ejemplares por nosotros examinados tienen grosores considerables (entre $12 \mathrm{~mm}$ y $13 \mathrm{~mm}$ ) y secciones rectangulares convexas. Las proporciones de 


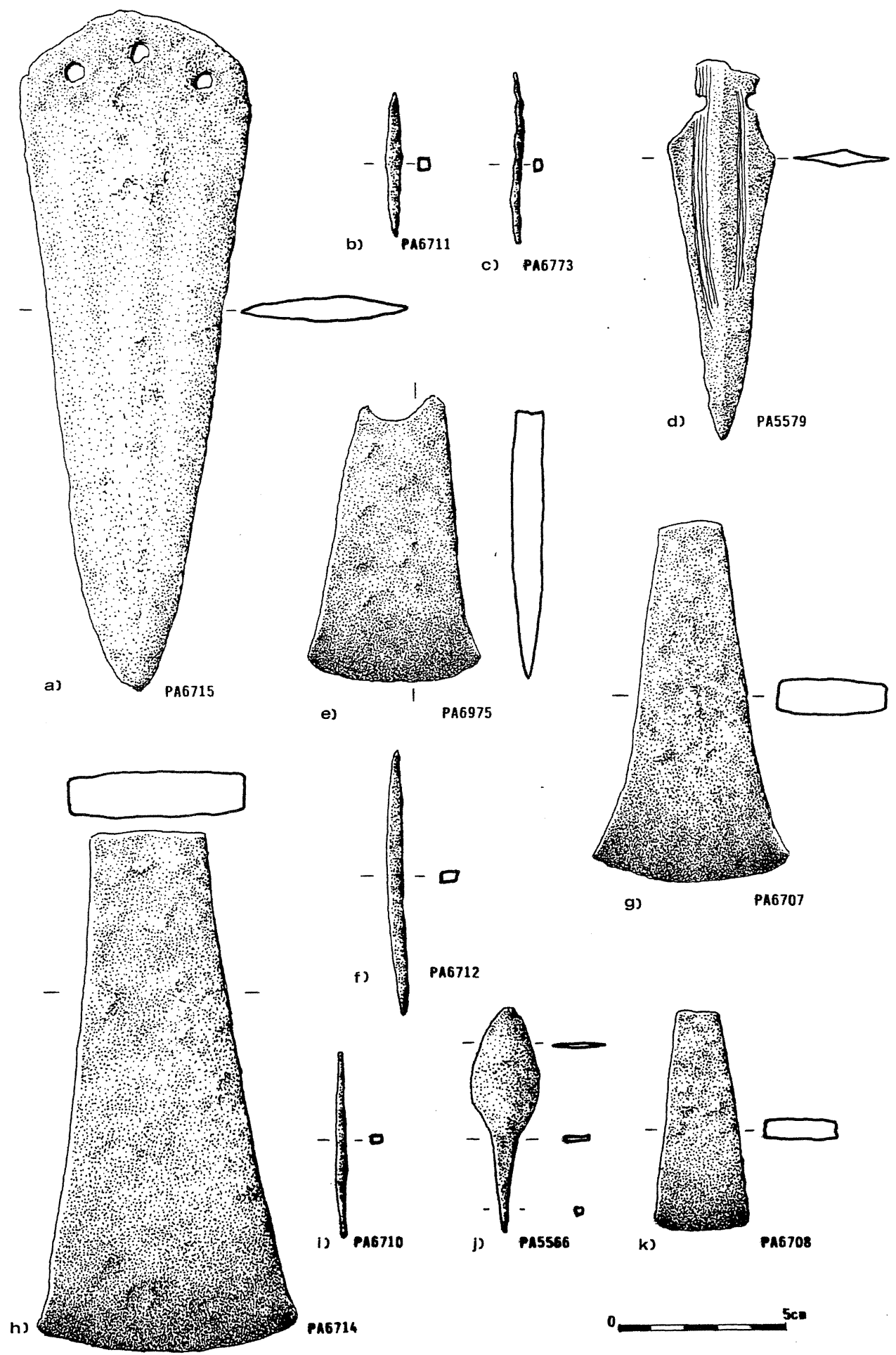

Fig. 2. a: Alabarda de Partida de las Naves (Teruel); b, c y f: Punzones de Frías de Albarracín (Teruel); d y j: Puñal de dos remaches y decoración y punta palmela de Las Alhambras (Teruel); e: Hacha de La Iglesuela (Teruel); g: Hacha del Cabezo Cariñera; h: Hacha de La Iglesia; i: Punzón de la Sima del Ruidor (Teruel); k: Cincel de la Sima del Ruidor (Teruel).

T. P., 53, n. ${ }^{\circ} 2,1996$ 
cobre oscilan entre el $96 \%$ y el $99 \%$, apreciándose normalmente un pequeño porcentaje de arsénico y en las dos de La Iglesuela del Cid de bismuto $(0,029 \%$ y $0,275 \%)$.

Hay un único cincel (Fig. 2 k) caracterizado por sus diminutas medidas en comparación con las demás hachas: $6,4 \mathrm{~cm}$ de longitud, $2,6 \mathrm{de}$ anchura máxima y $1,2 \mathrm{~cm}$ de mínima. Este tipo de "hachitas" o "cinceles" parecen más propio del Bronce Medio. Debemos tener en cuenta que en este caso el análisis espectrográfico detectó un $7,53 \%$ de estaño.

Conocemos tres puñales. Uno de ellos (Manzanera, Teruel) decorado (Fig. 2 d) parece ser la reutilización de espada corta o puñal-espada tipológicamente perteneciente a un Bronce centroeuropeo (Briard y Verron, 1976: fascículo II). Sus análisis demuestran el alto grado de la aleación broncínea $(\mathrm{Cu}=80,16 \%$ y $\mathrm{Sn}=18,89 \%$ ). Por otro lado, dos de ellos (el decorado y el hallado en Belchite) tienen dos remaches (Fig. $3 \mathrm{~g}$ ). Se les ha vinculado con un posible origen centroeuropeo (Unetice-Cultura Rodaniana) o ibérico (Argar) (Pérez Arrondo y López de Calle, 1986: 177). El de Belchite parece un bronce pobre con un $4,92 \%$ de estaño, mientras que el de Albarracín contiene un 3\% de arsénico. Asimismo, en la tercera campaña de excavaciones de El Castillo de Frías apareció un puñal de remaches completo. La descripción del mismo es: "...puñalito de bronce tipo triangular, con 3 remaches en la lengüeta..." (Andrés et alii, 1991: 48). Sin embargo, no lo hemos vuelto a ver mencionado o dibujado en otras publicaciones. Sin duda sería de gran interés su análisis en comparación con el fragmento de hoja que apareció en el nivel II de dicha excavación.

La alabarda de La Partida de las Naves (Alloza, Teruel) apenas tiene impurezas (tan sólo un $0,20 \%$ de As). Su clasificación como tal (Lull, 1983: 183-184) vino dada por sus dimensiones: $19,2 \mathrm{~cm}$ de longitud y $6,7 \mathrm{cms}$ de anchura máxima y por su nervadura central (Fig. 2a).

Las puntas palmela son piezas de la metalurgia ibérica que perduran durante un amplio período de tiempo. Las que hemos estudiado tienen el pedúnculo de sección rectangular, lo que se asemeja más a los tipos meseteños de Fuente-Olmedo (Valladolid) que a los salmantinos o sorianos de sección oval (Delibes de Castro,
1977: 109). Esta forma oval de la sección del pedúnculo parece más evolucionada que las formas en lente. En el mismo valle del Ebro las de Sakulo (Navarra), Carrascoso (Zaragoza) y Corral Quemado (Luesia, Zaragoza) son buenos ejemplos paralelizables a los de nuestra zona (Pérez Arrondo y López de Calle, 1986: 171).

\section{Bronce Tardío/Bronce Final}

Las puntas pedunculadas y con aletas son los tipos que más abundan, hallándose también en forma de moldes (2). De las cuatro puntas analizadas dos tenían una aleación de cobre y estaño con un porcentaje de $7,61 \%$ para la de Valdoria (Albalate del Arzobispo) y un 15,83\% para la de Moncín de Borja. Las otras dos pertenecientes a Majaladares y Moncín (ambos de Borja) son de cobre con una proporción de arsénico de $0,64 \%$ y $0,80 \%$ respectivamente (Fig. $3 \mathrm{c}, \mathrm{d}, \mathrm{e}, \mathrm{f})$.

Hay un único puñal de dos remaches procedente de Moncín de Borja (Pérez Arrondo y López de Calle, 1986: 190). Se clasifica como puñal-lanza, a nuestro parecer, injustificadamente, ya que es de dimensiones más pequeñas y su morfología general y de la punta recuerda totalmente a los puñales y no a las lanzas.

Los dos punzones también pertenecen a Moncín. Se clasifican como biapuntado y monoapuntado de sección cuadrada respectivamente.

Finalmente, tenemos 2 hachas con apéndices, una con anillas y un molde perteneciente a un tipo similar a esta última. El hacha de talón y anillas es de Teruel, pero su procedencia es desconocida. Su composición $(22,00 \%$ de estaño y $2 \%$ de plomo) parece adecuarse perfectamente a la tipología y composiciones típicas de las últimas etapas del Bronce Final. Las hachas de apéndices de El Castelillo de Alloza $(13,83 \%$ de estaño) y de La Iglesia (Iglesuela del Cid) $(20,89 \%)$ también pueden considerarse bronces de calidad.

Por otra parte, el hallazgo de 21 moldes diversifica un poco la tipología, añadiendo varillas, anillas, y cuchillos. Los moldes pertenecientes a las varillas, anillas y algún indeterminado están depositados en el Taller de Arqueología de Alcañiz y se supone proceden de los yacimientos de Siriguarach y Cabezo del Cuervo. 


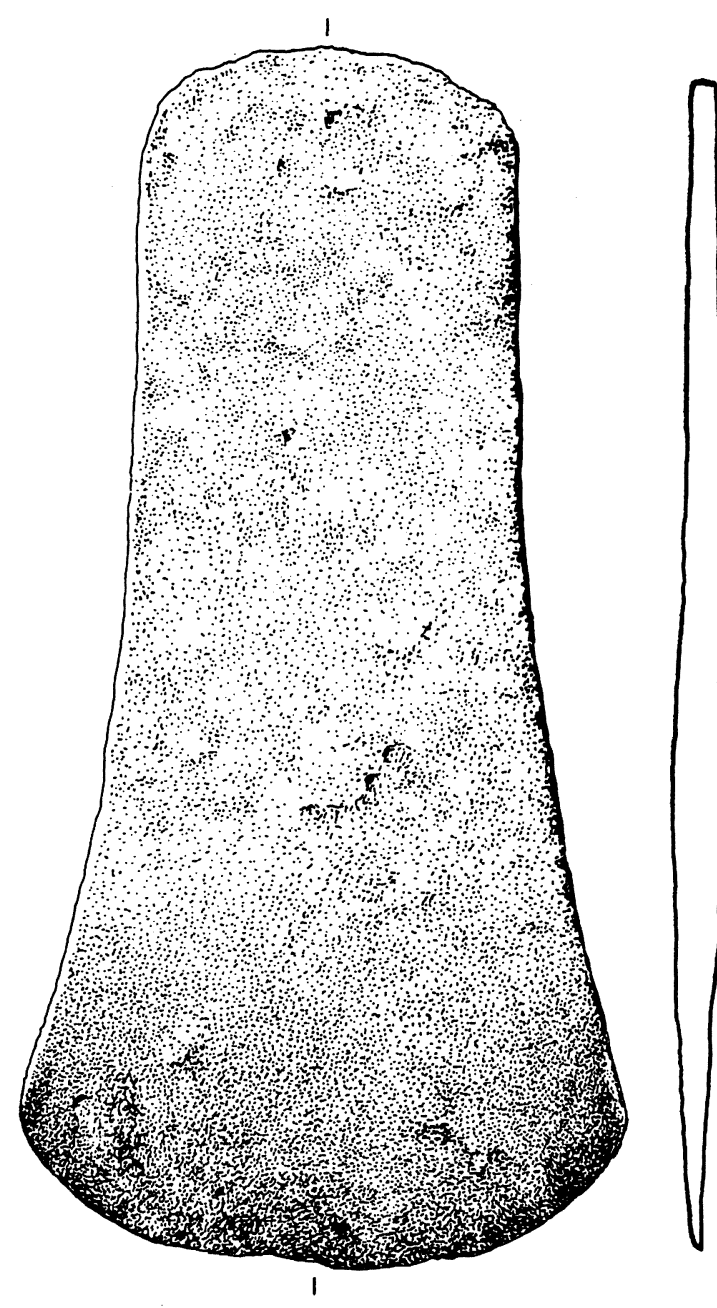

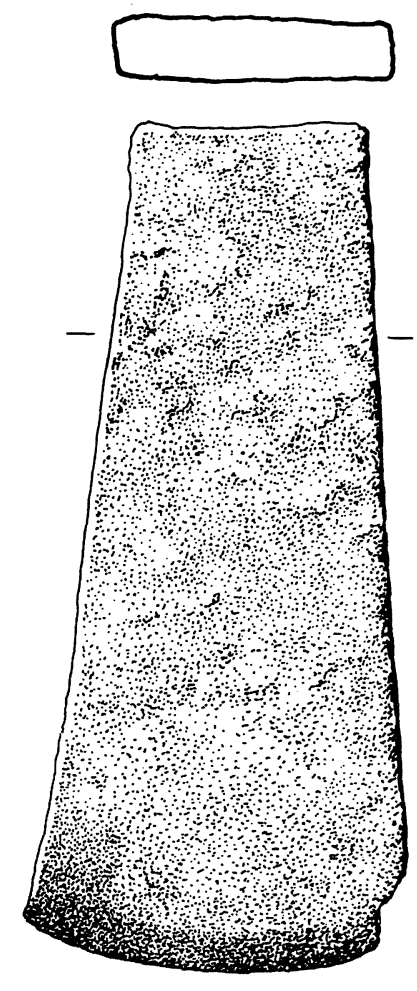

b)

PA5588

a)

PA\$586
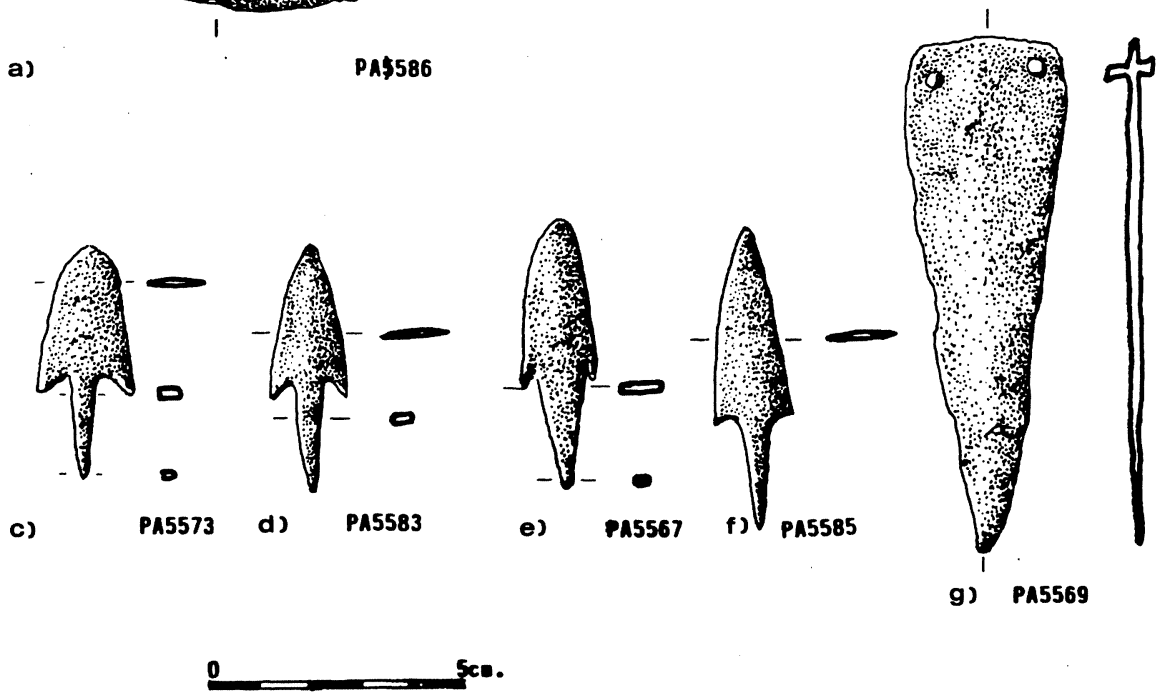

Fig. 3. a: Partida de las Naves (Teruel); b y f: Majaladares (Zaragoza); c y g: Cueva de los Encantados (Zaragoza); d: Borja (Zaragoza); e: Gelsa (Zaragoza).

T. P., 53, n. ${ }^{\circ} 2,1996$ 


\subsection{Valoración de la producción metalúrgica en el entorno meridional del Medio Ebro}

La producción metalúrgica aparece en el Sur de la Cuenca Media del Ebro durante el Calcolítico y sigue unos esquemas más o menos iguales hasta el llamado Bronce Medio, que es cuando se aprecia el inicio de un cambio. Pero, aun cuando la producción metalúrgica durante la Edad del Bronce aumenta considerablemente, no parece que las comunidades de este período dependiesen de ella. En el Bronce Antiguo y Medio, los tipos encontrados en el registro, herramientas-arma o armas (puñales, alabardas, punzones, hachas,...), parecen ser más un objeto de prestigio socio-ideológico, que un objeto necesario o imprescindible para la vida diaria. En el Bronce Final la diversificación y la proliferación de ciertos tipos hacen pensar en una pérdida de ese valor simbólico como consecuencia de esta generalización.

Las poblaciones debieron conocer las técnicas y las ventajas de la producción metálica. Los recursos no eran muy abundantes, pero existían y eran conocidos, aunque no fuesen explotados de forma continua ni exhaustiva. Las causas son difíciles de determinar pero posiblemente no les era necesario, ya que eran poblaciones tan arraigadas en tradiciones eneolíticas que no habían entrado aún en la dinámica de explotación de mineral y producción masiva.

Algunos investigadores han sugerido que esta zona adolecía durante la Edad del Bronce de un retraso tecnológico respecto a otras regiones situadas tanto en la Meseta Sur como en el Sureste. A mi juicio, no puede considerarse que las comunidades del Sur del Medio Ebro estuvieran sumidas en un "atraso". Estas poblaciones parecen conocer (a tenor de los vestigios estudiados) la tecnología extractiva, de procesado y producción, desde un momento bastante temprano. De vez en cuando la aplican, pero no se decantan por una producción mayoritaria. Creo que lo que sería sensato pensar es que estas comunidades tuvieron en cuenta el coste de extracción y producción en relación con las ventajas que iban a obtener.

Harrison (1994: 90) plantea que el nivel de producción e intercambio alcanzado no fue como para considerar que existieron grupos de artesanos especialistas o de metalurgistas a "tiempo completo", apuntando más hacia la existencia de una producción a escala doméstica. Nuestras evidencias, lamentablemente, no son lo suficientemente elocuentes como para poder hablar de los "talleres de metalurgistas" propuestos para otras zonas. Advertimos un modo y escala de la producción destinado exclusivamente a satisfacer la demanda interna, con independencia de que existiera una red de intercambios de productos de mejor factura.

En este punto deberíamos pararnos a pensar si hubo la suficiente demanda de aquellos objetos como para que se produjese una oferta. Hablar de oferta y demanda no siempre implica parámetros comerciales o económicos. La demanda de ciertos materiales y objetos puede producirse por motivos de prestigio o competencia (Shennan, 1989). Normalmente se compite por un bien cuando este es escaso o confiere prestigio. La reutilización de alguno de los objetos que hemos analizado hace pensar que la amortización del metal era necesaria, es decir, que el metal no era abundante al menos en forma de aleación elaborada. Esta misma amortización nos está exponiendo claramente la existencia de una demanda sin una oferta suficiente para atenderla. A tenor de esto se distingue: a. una demanda de objetos valiosos bien por su calidad, bien por el prestigio que conlleva poseerlos, b. una producción de objetos de menor calidad y con menores connotaciones simbólicas.

Un total de 94 objetos repartidos entre yacimientos de los tres subperíodos no parece ser un número elevado cuando hay unos 150 yacimientos de la Edad del Bronce localizados en la zona. De los 34 yacimientos analizados con elementos relacionados con la metalurgia, 21 pertenecen al período comprendido entre el Bronce Antiguo-Bronce Medio y 13 al Bronce Final. No todos han sido excavados y la superficie de los que sí lo han sido se puede estimar sólo en un 5-10\%. En los prospectados no tenemos datos del tipo de prospección que se llevó a cabo ni de la superficie prospectada, aunque de algunos sí se da noticia de que se llevaron a cabo catas. El Castillo de Frías de Albarracín (Teruel) cuenta con el número mayor de hallazgos en una misma etapa del grupo más anti- 
guo (Teruel): una punta de puñal, un puñalito completo, 3 punzones y un hallazgo suelto de hacha plana. En el más reciente ese lugar corresponde a Moncín de Borja (Zaragoza) con 5 puntas de flecha, 2 punzones, fragmentos de alambre y una hoja de afeitar.

\section{VALORACIÓN ECONÓMICA Y CULTURAL}

La muestra que hemos manejado es muy reducida, por ello las conclusiones que se pueden plantear sobre aspectos como el impacto medioambiental, las comunicaciones, o la función y papel de los metalurgistas en el contexto socioeconómico, tan sólo pueden ser tratados de forma tentativa. La futura aplicabilidad de nuestro modelo dependerá de la ampliación del bagaje de nuestros datos.

A tenor de lo expuesto y ciñéndonos a los datos manejados se pueden plantear las siguientes conclusiones:

1.- Que existen evidencias para afirmar que hubo actividades de extracción local de mineral de cobre en la época que tratamos y que su ejemplo es La Loma de la Tejería, Teruel; 2.- Además hubo un procesado del mineral y una producción local de objetos que se puede confirmar a partir de la comparación de los análisis de los minerales y de los objetos metálicos y del hallazgo de vasijas-horno/crisoles y moldes; 3.- A pesar de esto, el hallazgo de diferentes piezas metálicas de morfología centroeuropea parece establecer que hubo contactos que conllevaron la importación de artefactos con una composición y una manufactura diferente y, en muchos casos superior; 4.- La producción local debió de darse a escala doméstica, ya que en los yacimientos, por ahora, no se han encontrado vestigios de zonas especializadas en el procesado o la producción metalúrgica; 5.- El peso económico de las actividades metalúrgicas debió de ser bastante escaso en un principio, apareciendo quizás más como una actividad de prestigio que, llegando el final de la Edad del Bronce, iría modificando su importancia económica y social, así como ampliando la producción de los objetos, diversificándola y estandarizándola; 6.- A su vez la composición quí- mica y la tecnotipología de los artefactos metálicos analizados nos ha permitido definir dos períodos en la producción metalúrgica: el del Bronce Antiguo/Medio y el del Bronce Tardío/Final.

Con respecto a la función económica y social que pudieron representar los metalurgistas en el Sur de la Cuenca Media del Ebro tampoco se puede aventurar demasiado. Por los datos que tenemos: A. La metalurgia local no requeriría especialistas a tiempo completo, aunque los metalurgistas conocieran unas técnicas y supieran desarrollarlas cuando les fuere requerido. B. Tampoco parece que durante la Edad del Bronce, la producción metalúrgica fuera ni industrial ni estandarizada, sin que ello excluya la presencia de tipos semejantes en diferentes yacimientos. C. Quizás este conocimiento tecnológico les acercase al poder, pero con los datos que hasta el momento hemos manejado no es posible determinar que esta situación se diera. D. Probablemente las mismas comunidades que extraían el cobre eran las que posteriormente lo procesaban y producían, mientras que el estaño podría proceder de alguna clase de intercambio/transacción, ya que por ahora no se conocen menas cercanas (2).

\section{BIBLIOGRAFÍA}

Aguilera Aragón, I.; Harrison, R. y Moreno, G. (1992)a: "Excavaciones en Majaladares 1990 (Borja, Zaragoza)". Arqueología Aragonesa, 12: 90-93.

- (1992)b: "Excavaciones arqueológicas en 'Siete Cabezos' (Magallón, Zaragoza)". Arqueología Aragonesa, 12: $101-105$.

(2) Este artículo es parte de la Memoria de Licenciatura que se presentó el 29-V-1996 en el Departamento de Prehistoria de la Facultad de Geografía e Historia de la Universidad Complutense de Madrid. Debo agradecer a Gonzalo Ruíz Zapatero, Catedrático de Prehistoria de la Universidad Complutense de Madrid, la dirección de este trabajo y su apoyo y ánimo para que se publicase. A Ignacio Montero Ruíz, miembro del Departamento de Prehistoria del Centro de Estudios Históricos del CSIC, le estoy muy agradecida por sus comentarios tan pertinentes sobre la publicación de este artículo y, por su ayuda en general. Debo mencionar del mismo modo a las personas que en algún momento me han brindado su ayuda como M. ${ }^{a}$ Dolores Fernández-Posse, Concepción Martín, Salvador Rovira, y a los miembros del Departamento de Prehistoria de la Universidad de Zaragoza. Toda responsabilidad sobre el contenido del artículo revierte en mi persona. 
- (1994): "Excavaciones en Majaladares (Tarazona, Zaragoza)". Arqueología Aragonesa, 18: 135-139.

Almagro Gorgea, M. y Collado Villalba, O. (1981): "La Loma de la Tejería. Un asentamiento campaniforme en Teruel (Albarracín)". Teruel, 66: 13-25.

Álvarez Gracia, A. (1980-1982): "Notas sobre metalurgia del Bronce en el Valle del Ebro". Bajo Aragón Prehistoria, II: 41-51.

ANDrés Rupérez, T. (1990): "El Calcolítico y el Bronce Inicial y Medio". Estado Actual de la Arqueología en Aragón, I. Ponencias. Institución Fernando El Católico. Zaragoza: 71-96.

Andrés Rupérez, T. y Benavente Serrano, J.A. (1991): "Excavaciones en el Cabezo Sellado (Alcañiz, Teruel). Primera campaña 1986". Arqueología Aragonesa, 10: 128-131.

- (1992): "Informe sobre el estudio de materias del Cabezo Sellado (Alcañiz, Teruel)". Arqueología Aragonesa, 12: 45-47.

Andrés Rupérez, T.; Harrison, R. y Moreno, G. (1991)a: "Excavaciones en El Castillo de Frías de Albarracín (Teruel). 1988". Arqueología Aragonesa, 11: 79-86.

- (1991)b: "Excavaciones en el Castillo de Frías de Albarracín (Teruel). 1989". Arqueología Aragonesa, 11: 87-91.

ANDrÉs Rupérez, T. y Moreno LÓPEZ, A. (1985): "Yacimiento ‘El Castillo' (Frías de Albarracín)”. Arqueología Aragonesa, 5 : 152-153.

Atrian, P. (1974): "Un yacimiento de la Edad del Bronce en Frías de Albarracín”. Teruel, 52: 7-32.

BARANDIARAN, I. (1971): "Cueva de los Encantados (Belchite, Zaragoza”. Noticiario Arqueológico Hispánico, XV-XVI: 11-49.

BARANDIARAN, I. Y MARTÍN BUENO, M. (1971-1972): "Novedades sobre las edades de los metales en Aragón". Caesaraugusta, 35-36: 53-69. Institución Fernando El Católico.

BAss, G. (1967): Cape Gelidonya: a Bronce Age shipwreck. Transactions of the American Philosophical Society. Philadelphia.

Beltran, A. (1980): Atlas de Prehistoria y Arqueología de Aragón. Diputación General de Aragón. Zaragoza.

- (1980)b: "Aragón Prehistórico". Aragón en su Historia Caja de Ahorros de la Inmaculada, Zaragoza: 21-38.

Benavente Serrano, J.A. (1984)a: "Cambios geomorfológicos y distribución del hábitat prehistórico: una aplicación en los focos endorréicos del Bajo Aragón". Arqueología Espacial, 2: 53-74. Teruel.

- (1984)b: "La metalurgia prehistórica en Alcañiz y su entorno". Teruel, 72: 225-244.

- (1985-1986)a: "Prospecciones en el Cabezo Sellado. Alcañiz (Teruel)". Kalathos, 5-6: 9-31. Teruel.

- (1985-86)b: "Cuatro puntas metálicas procedentes de Odón (Teruel)". Kalathos, 5-6: 247-252. Teruel.

- (coord.)(1989): Catálogo de la colección Arqueológica de los Padres Escolapios de Alcañiz (Teruel). Diputación General de Aragón. Alcañiz.

Benavente Serrano, J.A. y Andrés Rupérez, T. (1992): "Informe sobre las excavaciones de Las Torra- zas (Alcañiz, Teruel). Campaña de 1990". Arqueología Aragonesa, 12, 1990: 58-61. Zaragoza.

Bernabeu, J.; Guitart, I. y Pascual, J. (1989): "Reflexiones en torno al patrón de asentamiento en el País Valenciano entre el Neolítico y la Edad del Bronce". Saguntun, 22: 99-123. Valencia.

BRIARD, J. y VERRON, G. (1976): Typologie des objects de l'Age du Bronze en France. Fascículo II. Société Préhistorique Française. Commission du Bronze. Paris.

Budd, P.; GAlE, N.; IXer, R. Y ThOMAS, R. (1994): "Tin sources for prehistoric bronze production in Ireland". Antiquity, 68, 260: 518-524.

Budd P.; Pollard, A.M.; Scaife, B. y Thomas, R.G. (e.p.): "Oxhide ingots, recycling and the Mediterranean metals trade". Journal of Mediterranean Archaeo$\log y, 7(2)$.

BudD, P. Y TAYLOR, T. (1995): "The faerie smith meets the bronze industry: magic versus science in the interpretation of prehistoric metal-making". World Archaeology, 27(1): 133-143.

Burgess, C. y Miket, R. (1976): Settlement and Economy in the Third and Second Millenia B.C. B.A.R. (British Serie), 33. Oxford

Burillo Mozota, F. y Picazo Millan, J. (1983): "La Hoya Quemada de Mora de Rubielos. Metodología para una excavación etnográfica y ecológica”. Diputación General de Aragón. Teruel.

- (1991)a: "Informe de la excavación arqueológica realizada en el poblado de la Hoya Quemada (Mora de Rubielos, Teruel). Campaña 1986". Arqueología Aragonesa, 10: 125-133.

- (1991)b: "Informe de la excavación arqueológica realizada en el Poblado de la Hoya Quemada (Mora de Rubielos, Teruel). Campaña de 1987”. Arqueología Aragonesa, 10: 134-137.

- (1991-1992): "Cronología y periodización de la Edad del Bronce en la Provincia de Teruel". Kalathos, 11-12: 43-89.

- (1992-1993): "Contribución al origen del poblamiento con estructuras estables en el valle Medio del Ebro". Bajo Aragón Prehistoria, IX-X: 203-214.

Carbonell Trillo-Figueroa, L. (1958): "Descripción minera de la Sierra de Albarracín". Teruel, 19: 5-30.

CRADDOCK, P. (1985): "The investigation of a small heap of silver smelting debris from Rio Tinto, Huelva, Spain". British Museum Occasional Paper, 48: 199-218. London.

Coffyn, A. (1985): Le Bronze Final Atlantique dans la Péninsule Iberique. Collection de la Maison des Pays Iberiques (GIS, 35), 20. Diffusion de Boccard, París.

Delibes de Castro, G. (1977): El Vaso Campaniforme en la Meseta Norte Española. Studia Archaeologica, 46. Departamento de Prehistoria y Arqueología de la Facultad de Filosofía y Letras de la Universidad de Valladolid: 101-116.

Delibes de Castro, G.; Fernández-Miranda, M.; FernÁndez-Posse, M.D.; Martín, C.; Rovira, S. Y SANZ, M. (1989): "Almizaraque (Almería): Minería y Metalurgia Calcolíticas en el Sureste de la Península Ibérica". En Claude Domerge (ed.): Minería y Metalur- 
gia en las Antiguas Civilizaciones Mediterráneas y Europeas. Ministerio de Cultura. Madrid. Tomo I: 81-96.

Domínguez Arranz, A. (1990): "Síntesis de la Edad el Bronce en las provincias de Zaragoza y Teruel". Bolskan, 7: 141-158.

FERnÁndeZ-Miranda, M.; Montero, I. y Rovira LloRENS, S. (1995): "Los Primeros objetos de bronce en el Occidente de Europa". Trabajos de Prehistoria, 52(1): 60-69.

Galan Huerto, E. y Mirete Mayo, S. (1971): Introducción a los Minerales de España. Instituto Geológico y Minero de España (IGME). Servicio de Publicaciones. Ministerio de Industria y Energía. Madrid.

García Serrano, J. (1995): "La Prehistoria en la Comarca del Moncayo". Turiaso, XI: 11-24.

GAllarT y FERnÁNDEZ, J. (1991): “El dipòsit de Bronzes de Llavorsí. Pallars Sobirà”. Departament de Cultura, Diputació de Lleida. Generalitat de Catalunya. Barcelona.

GALE, N.H. (1989): "Copper Oxhide Ingots: Their origin and Their Place in the Bronce Age metals Trade in The Mediterranean”. En Nöel H. Gale (ed.): Bronze Age Trade in the Mediterranean, Papers Presented at the Conference held at Rewley House, Oxford, in December 1989. En Studies in Mediterranean Archaelogy, XC: 197-239.

Genera, M.; Baucells, M.; Lacort, G. y Moura, M. (1985): "L'economia Protohistórica. Aspectes de la metallurgia al Priorat i a la Ribera d'Ebre". Pyrenae, 21: 45-56

GiL MASCARELL, M. (1995): "Algunas reflexiones sobre el Bronce Valenciano". Saguntum, 28. Homenaje a Miquel Tarradell i Mateu: 63-91.

Gómez Ramos, P. (1993): “Tipología de lingotes de metal y su hallazgo en los depósitos del Bronce Final de la Península Ibérica". Cuadernos de Prehistoria y Arqueología de la UAM, 20: 73-105.

- (1996): "Hornos de reducción de cobre y bronce en la Pre y Protohistoria de la Península Ibérica". Trabajos de Prehistoria, 53(1): 127-143.

HARRISON, R.J. (1994): "The Bronze Age in Nothern and Northeastern Spain. 2000-800 B.C.". En Clay Mathers and Simon Stoddart (eds.): Development and Decline in the Mediterranean Bronze Age, S.A.M., 8: 73-97.

Harrison, R.J.; Aguilera Aragón, I. y Moreno LÓPEZ, G. (1990): "Excavaciones arqueológicas en un poblado de la Edad del Bronce en $<<$ Siete Cabezos $>>$ (Magallón, Prov. Zaragoza)". Cuadernos de Estudios Borjanos, XXIII-XXIV: 31-59. Zaragoza.

HARrison, R.; Moreno LóPEZ, G. Y LeGGe, I. (1987): "Moncín: poblado prehistórico de la Edad del Bronce (I)". Noticiario Arqueológico Hispánico, 29: 9-111.

HARrison, R.; CradDOCK, P. y Hughes, J. (1981): “A Study of the Bronze Age Metalwork from the Iberian Peninsula in the British Museum". Ampurias, 43: 113-179.

Juste Arruga, M.N. (1990): El Poblamiento de la Edad del Bronce y Primera Edad del Hierro en Mora de Rubielos (Teruel). Monografías Arqueológicas del Seminario de Arqueología y Etnología Turolense, 3. Colegio Universitario de Teruel. Teruel.
Kristiansen, K. (1987): "Center and periphery in the Bronze Age Scandinavia”. En Michael Rowlands (ed.): "Centre and periphery in the Ancient World". New Directions in Archaeology. C.U.P. Cambridge: 74-85.

- (1989): "Prehistoric Migrations. The case of the Single Grave and Corded Ware Cultures". Journal of Danish Archaeology, 8: 211-225.

Lucas Pellicer, M.R. y Gómez Ramos, P. (1993): "Transporte marítimo del metal como materia prima durante el Bronce Final". Cuadernos de Prehistoria y Arqueología de la Universidad Autónoma de Madrid, 20: 107-131.

Lull, V. (1983): La Cultura del Argar. Akal editor. Madrid.

MARECHAL, J.R. (1985): "Methods of ore roasting and the furnaces used". British Museum Occasional Paper, 48: 21-28. London.

Martín-Bueno, M. y Pérez Arrondo, C.L.(1989): "Protometalurgia y metalogénesis en la Cuenca del Ebro". En C. Domenergue (cood.): Minería y Metalurgia en las Antiguas Civilizaciones Mediterráneas y Europeas I. Ministerio de Cultura. Madrid: 167-185.

MAya GonZÁlez, J.L. (1992): “Aprovechamiento del medio y paleoeconomía durante las etapas metalúrgicas del Nordeste Peninsular". En "Elefantes, ciervos, ovicaprinos. Economía y aprovechamiento del Medio en la Prehistoria de España y Portugal". Servicio de Publicaciones de la Universidad de Cantabria. Fundación Ortega y Gasset. Santander: 275-314.

MAZAR, A. (1990): "Archaeology of the Land of the Bible". The Anchor Bible Reference Library. Doubleday ed. New York.

MoHen, J.-P. (1991): "Métallurgie préhistorique. Introduccion à la paléométallurgie”. Ed. Masson, Paris.

Mohen, J.-P. y BAILloud, G. (1987): "La vie quotidienne. Les fouilles du Fort-Harrouard". En "L'Age du Bronze en France-4". Ed. Picard. París.

MonTEAgudo, L. (1977): Die Beile auf der Iberischen Halbinsel. Prähistorische Bronzefunde, IX, 6. München.

Montero Ruíz, I. (1989): "Minería prehistórica del Cobre: planteamientos de investigación". Cuadernos del Suroeste, 1: 7-10. Museo Provincial de Huelva y Museo minero de Riotinto. Huelva.

- (1993): "Bronze Age metallurgy in southeast Spain", Antiquity, 67: 46-57.

- (1994): El Origen de la Metalurgia en el Sureste Peninsular. Instituto de Estudios Almerienses. Almería.

- (1996): "Cerro Virtud. Indicios de actividad metalúrgica en el Neolítico". Revista de Arqueología, 178: 24-31.

Montero Ruíz, I. y Ruíz TABOADA, A. (1996): "Enterramiento colectivo y metalurgia en el yacimiento neolítico de Cerro Virtud (Cuevas de Almanzora, Almería)". Trabajos de Prehistoria, 53(2): 55-75.

MonTERo Ruíz, I.; RodríGUEZ, S. y RoJAS, J.M. (1990): Arqueometalurgia de la Provincia de Toledo: minería y recursos minerales de cobre. Diputación Provincial de Toledo. Toledo.

Pan Montojo, J.L. (1993): "Fuentes estadísticas". En M. Artola (dir.): Enciclopedia de la Historia de Espa$\tilde{n} a, 7$. Fuentes, Indices. Alianza Editorial. Madrid: $337-441$.

T. P., 53, n. ${ }^{\circ} 2,1996$ 
Pérez Arrondo, C.L. (1977): "Punzones metálicos de la Edad del Bronce en el Valle Medio del Ebro". Cuadernos de investigación. Geografía e Historia, III, 1 y 2. Publicaciones del Colegio Universitario de Logroño. Logroño.

Pérez Arrondo, C.L. y López de Calle, C. (1986): "Aportaciones al estudio de las culturas eneolíticas en el Valle del Ebro. II. Los orígenes de la metalurgia". Instituto de Estudios Riojanos. Historia/4.

Picazo Millán, J.V. (1986): El Eneolítico y los inicios de la Edad del Bronce en el Sistema Ibérico Central (Jiloca medio y Campo Romanos). Monografías del Seminario de Arqueología y Etnología Turolense, 1. Teruel.

- (1991)a: "Informe de la excavación realizada en el yacimiento de la Edad del Bronce de "Las Costeras" (Formiche Bajo, Teruel). Campaña 1988". Arqueología Aragonesa, 11: 103-107.

- (1991)b: "Informe de la actuación realizada en el yacimiento de "La Escondilla" (Villastar, Teruel)". Arqueología Aragonesa, 10: 111-117.

- (1991)c: "Excavaciones arqueológicas en "La Sima del Ruidor" (Aldehuela, Teruel). Campaña de 1986". Arqueología Aragonesa, 10: 119-125.

- (1991)d: "Informe de la excavación realizada en el yacimiento de la Edad del Bronce de La Peña Dorada (Alfambra, Teruel). Campaña 1987". Arqueología Aragonesa, 10: 93-96.

- (1991)e: "Informe de la excavación realizada en el yacimiento de la Edad del Bronce de Las Costeras (Formiche Bajo, Teruel) Campaña 1987)”. Arqueología Aragonesa, 10: 142-145.

- (1993): "La Edad del Bronce en el Sur del Sistema Ibérico Turolense, I: Los materiales cerámicos”. Monografías Arqueológicas del Seminario de Arqueología y Etnología Turolense, 7 . Teruel.

- (1994): "Informe de la excavación realizada en el yacimiento de la Edad del Bronce de Las Costeras (Formiche Bajo, Teruel) Campaña 1991". Arqueología Aragonesa, $17: 117-120$.

Picazo Millán, J.V. y Collado Villalba, O. (19891990): "Nuevas aportaciones para el estudio de la
Edad del Bronce en la Sierra de Albarracín (Teruel)". Kalathos, 9-10: 65-94.

Rovira, S.; Montero, I. y Consuegra, S. (1988): "Archaeometallurgical Study of Palmela Arrow Heads and Another Related Types". Elena Antonacci Sanpaolo (ed.): Archeometallurgia Ricerche e Prospettive. Atti del Colloquio Internazionale di Archeometallurgia. 18-21 ottobre 1988. Bologna-Dozza Imolese: 269289.

Ruíz-GÁlvez Priego, M. (1995): "Ritos de Paso y Puntos de Paso. La Ría de Huelva en el Mundo del Bronce Final Europeo". Complutum Extra, 6. UCM. Madrid.

Ruíz Zapatero, G. (1982): "El poblado protohistórico de Siriguarach (Alcañiz, Teruel)”. Teruel, 67: 23-54.

- (1985): "Los Campos de Urnas del NE de la Península Ibérica". Tesis Doctoral. Editorial de la Universidad Complutense de Madrid. Madrid.

Shennan, S. (1992): "Population, Prestige an Production: some aspects of the Development of Copper and Bronze Metallurgy in Prehistoric Europe". Festschrift zum 50jährigen Bestehen des Institutes für Ur- und Frühgeschischte der Leopold-Franzens-Universität. Innsbruck: 535-542.

SherRATT, A. (1976): "Resources, technology and trade: an essay in early European metallurgy". En Sieveking, Longworth \& Wilson (eds.): Problems In Economic and Social Archaeology. Duckworth Ed. Londres : 557582.

SimÓN Domingo, J.M. (1987-1988): "Tres excavaciones de urgencia en Cuencas Mineras Turolenses". Kalathos, 78: 63-87. Teruel.

Tylecote, R.F. (1986): "The Prehistory of Metallurgy in the British Isles". The Institute of Metals. London. $2^{\mathrm{a}}$ ed. 1990.

Vilaseca Anguera, S. (1973): "Reus y su entorno en la Prehistoria". Asociación de Estudios Reusenses. Edicions. Rosa de Reus. Reus.

VV. AA. (1994): "La minería de Aragón”. Diputación General de Aragón. Departamento de Industria, Comercio y Turismo. INO Reproducciones, S.A. Zaragoza. 